\title{
Trends of Management Rationalization
}

\section{in Japanese Steel Industry}

\author{
By Naonori Sumino**
}

\section{Introduction}

The Japanese steel industry, the prime mover of the nation's industrial advance, has developed at a remarkably rapid pace in the course of the past few years, highlighting the amazingly high rate of Japan's economic growth which is now the focal point of world-wide attention. In 1960, another important milestone was reached in further promoting Japan's position in the international economic community when her crude steel production rose to $22,140,000$ metric tons, which represented an increase of 33 per cent over the preceding year-the highest rate of increase attained throughout the world. This indeed far surpasses the production increase of 15 to 20 per cent which was registered in European countries during the same year under booming market conditions.

The speedy growth of Japan's steel industry is expected to continue in the future. As is well known, the Economic Council, in the recommendations it put forward last year in response to the Government's national income doubling plan, envisages 48,000,000 metric tons of domestic iron and steel requirements on the crude steel basis in 1970. Based on this demand estimate, steel manufacturers across the country at present are steadily pressing forward with the modernization and expansion of their production facilities. In view of these developments, it would be fair to state that there is now a very definite possibility of Japan's coming to rank as the world's third largest steel producer, next to the United States and the Soviet Union, within 10 to 15 years.

As it is, the fact must not be overlooked that the supplying capacity of steel industries overseas is also being greatly increased under the spur of the world's fast-growing steel requirements. The intensification of international competition resulting therefrom by no means warrants optimism over the future prospects but makes it imperative for the Japanese steel industry to further strengthen its management setup on an integrated, all-round basis through the enforcement of various rationalization measures.

\section{Factors Prompting Rationalization}

\section{Progress of Postwar Rationalization}

Let us now look back on the path of rationalization thus far followed by the Japanese steel in- dustry. A series of rigorous economic reform measures, put into force in 1949 under the so-called "Dodge Line" of anti-inflationary policy, brought the industry face to face with the problem of rationalization for the first time after the end of World War II. Deprived thereby of the benefits of the "price difference subsidy" system which had so far served as a prop for its rehabilitation, and with new restrictions imposed on the use of imported raw materials, the industry was now compelled to buckle down to the task of rationalizing its facilities and operations.

Under the Dodge Plan whose objective lay in arresting the onslaught of postwar inflation through balanced budgetary programs and in relinking the Japanese economy to the international economy by establishing a single exchange rate, it became an urgent problem for Japan to promote exports and thereby solidify the foundation of her economic self-reliance. A spate of discussions ensued on the ways and means of achieving these ends. The Japanese steel industry at the time, however, lacked sufficient ability to withstand international competition in respect of both price and quality of products, and a thorough-going modernization of production facilities obviously was the only way out of this fundamental backwardness. It was on the basis of this recognition that the industry carried out the gigantic First Rationalization Program, involving total investments of 120 billion yen, in the 1951-55 period.

The subsequent years saw a continued skyrocketing of the demand for iron and steel at home and abroad, calling for further production increases and technological improvements, and accordingly the Japanese steel industry executed the Second Rationalization Program, at a total cost of 450 billion yen, during a period of approximately five years beginning in 1956. The successful completion of the second program has resulted in a marked increase in the productive capacity of various companies centering around the construction of new, fully integrated steel mills.

Since the year before last, various steel manufacturing companies here have announced and embarked upon new long-term facilities investment plans one after another, with the intention of readjusting their production setups to the long-range forecast of iron and steel requirements. As is widely known, these individual investment plans, estimated to cost three trillion yen in all, make up what is collectively called the Third Rationalization Program of the Japanese steel industry.

* Lecture delivered before the 61st Grand Lecture Meeting of the Iron \& Steel Institute of Japan on April 5, 1961 in

Tokyo. Japanese text was printed in "Tetsu-to-Hagané" (Journal, Iron \& Steel Institute, Japan) Vol. 47, No. 7, pp. 951-955.

** Executive Vice President, Yawata Iron \& Steel Co., Ltd. 


\section{Problems Confronting Steel Industry}

In the foregoing, we have attempted a brief review of the factors that have served to spur rationalization in the Japanese steel industry since the war's end. Let us now turn to some of the problems currently confronting the industry.

\section{i. Intensification of International Competition}

The first problem that comes to one's mind in this connection is the intensification of international competition which is expected to result from the progress of world-wide trade liberalization and the "dollar defense" policy recently adopted by the United States.

In the wake of the GATT General Meeting of November 1959, which sparked lively discussions on the trade liberalization issue in this country, the Japanese Government in January, 1960, decided on a basic policy of expediting trade liberalization, simultaneously announcing measures to relax exchange restrictions. Again in June, the Government made public the "Outline of Trade and Exchange Liberalization Program", thus steadily pressing toward a freer foreign trade setup. Moreover, the changes brought about in the international situation due to the recent switchover of Britain, West Germany and France to the "Article 8 Nations" group of the International Monetary Fund has had the effect of further accelerating the tempo of trade liberalization throughout the world, making it necessary for Japan to rescrutinize even some of the liberalization programs she had previously mapped out. With regard to the steel industry, these liberalization programs have been implemented in the form of a full switchover of the import of iron scrap, pig iron and ordinary steel products to the Automatic Approval System, effective April and October 1960, and June this year, respectively, with the former restrictions on purchases from the dollar area having been completely lifted.

Meanwhile, the United States whose gold reserve saw an alarming decrease on account of her huge expenditures in postwar foreign aid and capital exports has put into effect since the end of last year a series of dollar-saving measures, including a drastic reduction of her off shore military procurements and a switch to the "Buy American" policy in foreign economic aid.

The effect of these measures on the Japanese steel industry, directly, will be a decline of procurements with the DLF (Development Loan Fund) and ICA (International Cooperation Administration) funds, and, indirectly, an intensification of competition with European and American steel makers in the export markets.

How strong is the international competitive power of Japan's steel industry in the light of this situation?

In point of prices, ordinary steel produced by Japan is priced at the international average or somewhat lower. This should cause no optimism, however, for it is customary with most West European nations to resort to a dual pricing system as a means of export promotion.

With respect to production costs, the problem boils down in the last analysis to the price level of raw materials which is the principal component element of production costs. In the case of the Japanese steel industry, which relies heavily on foreign sources for supplies of raw materials, a matter of greatest concern is the instability of the price of imported raw materials.

By technological standards, on the other hand, it can be said that the Japanese steel industry today is fully comparable with its American and European counterparts as far as the manufacture of ordinary steel is concerned. Special steel made in this country, however, still lacks the ability to compete on the international market at present.

In regard to management ability, a major drawback of the Japanese steel industry is the excessively low ratio of owned capital to borrowed capital in individual enterprises which, by increasing the burden of capital cost and suppressing the profit-earning power, weakens the resiliency of the enterprises to cope with market fluctuations and diminishes their international competitive power.

Thus viewed, the steel industry of this country, though considerably strengthened through efforts up to the present, must still be said to embrace various internal weaknesses.

\section{ii. Market Encroachment by Competitive Materials}

The second problem which currently faces not only Japan's steel industry but steel industries throughout the world is the debut of various new materials as competitors of iron and steel. One of those competitive materials is aluminium which, because of its qualitative advantages such as light weight, resistance against corrosion and the beauty of surface, has come to invade the traditional field of iron and steel consumption to a considerable extent of late. However, aluminium is still unable to offer full-scale competition with iron and steel because of the cost factor, and its use is largely confined to certain special fields at present.

Plastics, which are light, corrosion-proof and easily moulded, are considered to have even greater possibilities than aluminium as substitutes for iron 
and steel. Plastic materials currently encroaching upon the iron and steel market include vinyl chloride, polyethylene and polyester resins. It is expected that further advances on the chemical industry in the future will make available plastic materials of higher quality at lower costs. Consequently, a sizable amount of steel products such as pipes and sheets will be replaced by plastic products.

Although the steel industry has recently launched a "rollback" against market encroachment by these competitive materials by redoubling its efforts for the development of new products, this still remains a serious problem that needs to be closely watched.

Thus, we find that behind the steady growth of the Japanese steel industry, there still lie a number of problems to be solved. In the following, I should like to briefly describe management rationalization measures needed to cope with these problems.

\section{Trends of Management Rationalization}

\section{Higher Ratio of Owned Capital in Enterprises}

The first prerequisite to management rationalization is a "constitutional improvement" in enterprise finance, which in turn presupposes, first of all, a higher ratio of owned capital in individual enterprises.

Since Japan's steel industry has largely depended on borrowed capital for effecting facilities expansion to meet soaring postwar demands, its capital composition is markedly inferior compared with prewar days or with steel industries overseas.

When the progress of trade liberalization in the period ahead is taken into consideration, it is evident that a higher ratio of owned capital in individual enterprises is essential for strengthening the resistance of enterprises to changing business conditions as well as for solidifying the basis of autonomous management. This can be achieved by two means, capital increase and intra-company reservation of profits.

In order to be able to carry out a capital increase, an enterprise must in the first place firmly maintain a certain level of dividends and arrange a system to secure the profit-earning power to guarantee stable payment of the dividends. In this connection, it is to be hoped that the Government will rectify the defects of the existing taxation system under which it is more advantageous to procure funds by borrowing than by effecting capital increases.

For the purpose of encouraging intra-company reservation, the present depreciation standards need to be re-examined.
A restudy of the existing depreciation system is necessitated, for one thing, by the fact that the appraised value of the assets of the Japanese steel industry, which were earmarked for depreciation prior to 1953, is unduly low in the light of the current price level.

For another thing, today when new facilities are quickly made obsolete due to rapid technological innovations, there is a world-wide tendency in favor of the adoption of an accelerative depreciation formula, and I believe that in Japan also, more consideration should be given to realizing shortterm depreciation of fixed assets of business enterprises.

To sum up, what I wish to stress here is the need of directing, insofar as possible, the financing for future rationalization investments toward dependence on stable and long-term funds.

\section{Positive Cultivation of Markets}

The second step to be taken toward this end is a positive study and cultivation of markets.

The Japanese steel industry until the end of the war developed under State protection with huge munition requirements as a background. In the postwar days, however, the steel industry has undergone a complete change of character, converting itself into an export industry relying chiefly on civilian demands and charged with the task of earning foreign currency. At the same time, the industry's productive capacity has been greatly expanded, and this has been accompanied by an intensification of sales competition both in domestic and overseas markets. As a result, the industry is now confronted with the pressing need of making vigorous efforts for research and cultivation of markets at its own risk.

In this connection, it is most gratifying to note that various steel manufacturing companies here have recently initiated serious efforts for research and cultivation of steel markets from a long-range viewpoint, since accurate business forecasts are the first essentials for sound management. In marketing research and market cultivation, it is of paramount importance, as I have already stated, to view the future not only from the standpoint of the steel industry but also from that of rival industries. Only by so doing can the future of the steel industry be clearly illumined in relief, and effective and proper measures put into action to ensure stable operations.

As measures for promoting the steel industry's development on a long-range basis and for stimulating active demands for steel products, technical services for users and publicity campaigns to arouse stronger public interest in iron and steel 
can be considered.

As regards technical services, they have up to now been rendered chiefly in the form of afterservice. In order to tide over the intensification of competition in the years to come, however, it is necessary to go a step further and endeavor to find out, from the users' standpoint, what products are truly desired by the users, so that their needs may be promptly filled.

In the prewar period, because of the character of iron and steel as typical capital goods, the steel industry failed to make sufficient efforts to enlighten the general public concerning its significance and function. In the light of the importance of the position which the steel industry is destined to occupy in the national economy henceforth, however, "public relations" activities clearly merit special attention and efforts. It is my belief that the basic tenor of publicity campaigns to be conducted by the steel industry from now on should be such as to break the old notion in the minds of the public that "iron is heavy, black and difficult to handle", and to implant in its place a new image of iron that is "light, strong, beautiful and easy to handle". It must not be forgotten that due to the markedly increased use of iron and steel in the manufacture of durable consumer goods after the war, the distance between steel makers and the consumer public has been greatly shortened today.

\section{Technological Improvements}

The third factor in management rationalization is technological improvements.

\section{i. Elevation of Technological Level}

While the facilities of the Japanese steel industry have now reached the international level owing to the facilities rationalization effected in two stages since the war's end, these modernized facilities, though they indeed are an embodiment of the current technological innovation, cannot be utilized to the full extent of productivity they are designed for, unless the industry commands a correspondingly high level of production techniques.

By technological standards, the Japanese steel industry today keeps abreast with steel industries of advanced nations overseas and has attained the world's highest record in the reduction of the coke ratio and heat consumption per unit of production in the open hearth process.

However, with full-scale trade liberalization scheduled to take place in the immediate future, we should now renew our determination to devote ceaseless efforts to the cultivation of techniques that will enable us to make the most of our latest facilities.
The need of shifting the center of gravity of Japan's industrial structure to the heavy and chemical industries is frequently pointed out nowadays. To realize this, it is necessary for the steel industry to supply the machinery industry and other kindred industries with high-quality steel materials at low prices, thereby strengthening the international competitive power of those industries, as well as its own, under the principle of coexistence and coprosperity. In particular, steel manufacturers are urged to redouble their efforts for qualitative improvement of products in the field of special steel, the machinery industry demand for which is expected to see a big increase in the future.

\section{ii. Advance of Basic Research}

In order for the steel industry to fulfill this mission, it must not idly remain dependent on techniques imported from overseas but must positively carry out development research on its own initiative.

Technical research in this country, which has hitherto consisted chiefly in improvement research made on requests from workshops, should be broadened in scope and be aimed at the development of new techniques if it is to serve for the development of the steel industry in this age of phenomenal technological progress. It is with this objective in mind that various steel companies in Japan have newly established central research institutes or have expanded existing research facilities one after another of late, and my opinion is that the activities of these research organs, in the interest of the industry as a whole and of the nation, should be organically coordinated in the future, through well-planned sharing of research fields and through the exchange of research results.

\section{iii. Training and Education of Technical Workers}

For the effective execution of the various measure described in the foregoing, a large number of highly skilled technicians and engineers are required. It is pointed out in the Government income doubling plan that manpower shortage is likely to become a restrictive factor to hamper the growth of the national economy in the future. To prepare against this, the steel industry, taking the lead of other industries, has formulated various countermeasures including the foundation of a Steel Seminary within the industry. Of course, it goes without saying that more far-reaching measures need to be enforced in cooperation with the Government authorities for the fundamental solution of this problem. 


\section{Strengthening of Control System}

Fourthly, the trend of management rationalization is toward the strengthening of the control system.

\section{i. Establishment of Long-Range Management Programs}

Above all, this calls for the establishment of long-range management programs. At the present day when enterprise activities are liable to be heavily affected by changes in social conditions and the operational scale of enterprises is being steadily enlarged, it is essential for the stable development of an enterprise to conform its management to a criterion prescribed for the coordination of the activities in all the branches of the enterprise, on the basis of long-range and scientific business forecasts.

\section{ii. Practical Application of Industrial Engineering}

The expansion of the operational scale of individual enterprises, in the steel industry as in other industries, is expected to bring their capital requirements to a huge amount. This means that a bigger and bigger risk is going to be involved in the determination of executive policies. In order to cope with this situation, the management of an enterprise must necessarily be placed on a scientific basis. It is for this reason that I am convinced of the urgent need of positively encouraging practical application of "industrial engineering" (IE) techniques to management.

\section{iii. Modernization of Control Methods}

Effective utilization of modernized facilities can not be anticipated unless the machinery of management has full control over them. It is therefore necessary to work out sufficiently flexible control methods, allowing for the special characteristics and conditions of individual enterprises. At Yawata Works of Yawata Iron \& Steel Co., Ltd., for example, a new control formula based on the "linestaff" system was adopted in September, 1958, on the occasion of the new, fully integrated Tobata mills coming in operation. Until then, supervisors at the plant, charged with both line and staff duties, had been overburdened with miscellaneous work and the overlapping and confusion of their functions had been hampering the smooth operation of the modernized facilities. To remedy the situation, a reorganization of the supervisory organ was effected on a functional basis. As a result of the division of the line and staff functions between respective experts thus attained, efficiency was increased and manpower requirements were reduced.
Notably, this made possible the concentrated, effective utilization of the services of collegeeducated technical workers with regard to whom manpower shortage had been most keenly felt.

Another salutary effect of the reorganization was that the line supervisors at the plant, relieved of cumbrous staff duties, were enabled to concentrate on their normal plant control duties, while the path was opened for the promotion of ordinary operatives within the line organization to subforeman, foreman and to plant manager, serving materially to promote their morale. This being an entirely new attempt, there of course remain several problems that still need to be worked out, such as qualitative improvement of foreman, education of staff members and the enhancement of smooth exchange of views between line and staff members. Nevertheless, it is my belief that the organizational reform made at Yawata Works has much to suggest about the future trend of management control methods.

\section{Closer Cooperation with Related Industries}

Fifthly, mention must be made of closer cooperation with related industries.

It can be said that the steel industry of this country, the development of which historically depended upon requirements for war material, has not been very closely tied to consumer industries up to the present. However, tightening of its cooperative setup with related industries is now an indispensable precondition to the steel industry's attaining a stronger competitive power in the face of the imminent trade liberalization. It will not only enable the steel industry to secure a stable market for its products but will also bring about such benefits as close adjustment of supplies to requirements through the mutual exchange of information relating to production techniques stabilization of management through the levelling of annual profits, and the strengthening of export power with a bigger capital. Recently, this trend has come to manifest itself in the formation of "kombinats" in varirous parts of the country. "Kombinats" refer to the regionally combined bodies of different types of enterprises which are designed for management rationalization through mutual cooperation and are aimed at attaining such results as the elimination of waste in the use of raw materials, reduction of transportation expenses and full utilization of the respective technical advantages of component enterprises.

In the steel industry also, there is an active move for the formation of "kombinats" with the chemical industry. These are expected not only to contribute substantially to the conservation of raw material 
resources by making it possible to effectively utilize as raw materials for the chemical industry such by-products of steel making as coke oven gas, blast furnace gas, coal tar and slag which are expected to be produced in large quantities as steel output increases in the coming years, but will also play an important role in reducing the production costs in the related industries.

Furthermore, it is my opinion that the steel industry from now on should strive also for the formation of "kombinats" with other steel-using industries such as machinery, shipbuilding and automobile, and comprehensive programs formulated for organically binding together all these related industries, so that each industry may enjoy the benefits of reduced costs and qualitative improvement of products.

\section{Solidification of Intra-Industry Cooperative Setup}

Finally, I should like to cite the need of solidifying the cooperative setup within the steel industry itself.

The steel manufacturers of Japan have already significant achievements in promoting mutual benefits through intra-industry cooperation by employing such means as the open sales system, and the organization of a scrap cartel and an export association. In view of the fortheoming trade liberalization and the resultant intensification of international competition, however, the need is ever more keenly felt for strengthening the basis of the Japanese steel industry's stable development through a further tightening of the intra-industry cooperative setup in all the fields of the industry's activities, including the formulation of facilities installation programs, procurement of raw materials, stabilization of the price of products and the expansion of markets. If individual enterprises should take self-seeking action in disregard of this need, it would immediately lead to an excessive competition, which would not only be suicidal to the steel industry itself but would cause immeasurable losses to the national economy in its entirety. In this connection, it is earnestly hoped that all those who are connected with the steel industry will once again reflect on the importance of the mission assigned to them and endeavor seriously to map out measures to secure industry's prosperity based on mutual trust and cooperation.

\section{Conclusion}

In the foregoing, I have stated my views concerning the problems currently confronting the Japanese steel industry and the ways and means of solving them. Recently, my attention was at- tracted by an article discussing the future of the U.S. steel industry, which appeared in the December 1960 issue of "Fortune" magazine. The article warned that although the American steel industry probably would continue to experience a considerable growth during the next decade at least, there would eventually come a day when it finds itself on a downhill path. Pointing out that the U.S. steel production since 1955 has dropped by 13 per cent whereas there has been an actual increase of gross national product by 12 per cent, the article attributed this primarily to the rise of the price of steel products which has outpaced the price rise of other industrial products and which consequently opened the way for the encroachment of the established steel products market by such competitive materials as aluminium, plastics and concrete, as well as to the marked reduction in steel consumption which has been brought about by newly developed engineering and designing techniques. Naturally, the U.S. steel industry has launched all-out efforts to restore its former prosperity against these developments, by revamping its traditional sales policy and by positively embarking upon a new marketing strategy and the development of new technology.

Although I do not believe that the steel industry of Japan would follow the same fate in the near future, we nevertheless ought to take a lesson from this fact and modestly reflect upon the present conditions of management in the industry.

At any rate, while the future path of the Japanese steel industry can by no means be said to be smooth, great expectations are placed in the heavy and chemical industries, the steel industry in particular, as the mainstay of the nation's economic prosperity in the years ahead, and this makes us keenly feel the importance of our assigned mission to press ahead further with the rationalization of the steel industry. 